\title{
Erratum to: Physical properties of particulate matter from animal houses - empirical studies to improve emission modelling
}

\author{
Ehab Mostafa ${ }^{1,2}$. Christoph Nannen ${ }^{2} \cdot$ Jessica Henseler $^{2} \cdot$ Bernd Diekmann $^{3}$. \\ Richard Gates ${ }^{4}$. Wolfgang Buescher ${ }^{2}$
}

Published online: 10 May 2016

(C) Springer-Verlag Berlin Heidelberg 2016

Erratum to: Environ Sci Pollut Res

DOI 10.1007/s11356-016-6424-8

The original article was corrected. The name Gregor

Schmitt-Pauksztat was added to the author list by mistake.

The online version of the original article can be found at http://dx.doi.org/ 10.1007/s11356-016-6424-8.

Ehab Mostafa

ehababdelmoniem@hotmail.com

1 Agricultural Engineering Department, Faculty of Agriculture, Cairo University, El-Gammaa Street, 12613 Giza, Egypt

2 Institute for Agricultural Engineering, Bonn University, Nussallee 5, 53115 Bonn, Germany

3 Institute of Physics, Bonn University, Nussallee 12, 53115 Bonn, Germany

4 Agricultural \& Biological Engineering, University of Illinois, 360C AESB, 1304 W. Pennsylvania Ave, Urbana, IL 61801, USA 